\title{
Molecular synthesis in ices triggered by dissociative electron attachment to carbon monoxide
}

\author{
Fabian Schmidt(D, Martin Philipp Mues(D), Jan Hendrik Bredehöft(D, and Petra Swiderek ${ }^{\mathrm{a}}$ (D) \\ Fachbereich 2 (Chemistry/Biology), Institute for Applied and Physical Chemistry, University of Bremen, Leobener Straße \\ 5, 28359 Bremen, Germany
}

Received 1 September 2021 / Accepted 10 November 2021 / Published online 2 December 2021 (C) The Author(s) 2021, corrected publication 2021

\begin{abstract}
Chemical reactions in mixed molecular ices as relevant in the context of astrochemistry can be initiated by electron-molecule interactions. Dissociative electron attachment (DEA) as initiating step is identified from the enhancement of product yields upon irradiation at particular electron energies. Herein, we show that DEA to $\mathrm{CO}$ leads to the formation of $\mathrm{HCN}$ in mixed $\mathrm{CO} / \mathrm{NH}_{3}$ ice at electron energies around $11 \mathrm{eV}$ and $16 \mathrm{eV}$. We propose that this reaction proceeds via insertion of the neutral $\mathrm{C}$ fragment into a $\mathrm{N}-\mathrm{H}$ bond. In the case of $\mathrm{CO} / \mathrm{H}_{2} \mathrm{O}$ and $\mathrm{CO} / \mathrm{CH}_{3} \mathrm{OH}$ ices, a resonant enhancement of the yields of $\mathrm{HCOOH}$ and $\mathrm{CH}_{3} \mathrm{OCHO}$, respectively, is observed around $10 \mathrm{eV}$. In both ices, both molecular constituents exhibit DEA processes in this energy range so that the energy-dependent product yield alone does not uniquely identify the relevant DEA channel. However, we demonstrate by comparing with earlier results on mixed ices where $\mathrm{CO}$ is replaced by $\mathrm{C}_{2} \mathrm{H}_{4}$ that DEA to $\mathrm{CO}$ is again responsible for the enhanced product formation. In this case, $\mathrm{O}^{-}$activates $\mathrm{H}_{2} \mathrm{O}$ or $\mathrm{CH}_{3} \mathrm{OH}$ which leads to the formation of larger products. We thus show that DEA to CO plays an important role in electron-induced syntheses in molecular ices.
\end{abstract}

\section{Introduction}

Electron-molecule interactions are typically associated with their dissociative nature which has been studied for many cases and reviewed repeatedly [1-8]. However, when these interactions occur in dense environments, reactive species resulting from such electroninduced dissociation can undergo further chemical reactions. This leads to the formation of new products [911] or can be exploited to fabricate novel materials with interesting properties $[12,13]$. Electron-induced chemical processes also receive attention with respect to research on the origin of organic molecules in space. It is nowadays recognized that low-energy electrons released under the effect of ionizing radiation can drive much of the interstellar chemistry within molecular ice layers that form on the surface of cold dust grains $[11,14,15]$.

In fact, electron-molecule interactions can trigger reactions that lead to the synthesis of larger molecules from smaller building blocks. In ideal cases, the products can even incorporate all atoms of the initial reactants [16]. As prototypical examples, the syntheses of ethylamine $\left(\mathrm{C}_{2} \mathrm{H}_{5} \mathrm{NH}_{2}\right)$ from ethylene $\left(\mathrm{C}_{2} \mathrm{H}_{4}\right)$ and ammonia $\left(\mathrm{NH}_{3}\right)$ [17], ethanol $\left(\mathrm{C}_{2} \mathrm{H}_{5} \mathrm{OH}\right)$ from ethylene $\left(\mathrm{C}_{2} \mathrm{H}_{4}\right)$ and water $\left(\mathrm{H}_{2} \mathrm{O}\right)$ [18], as well as formamide $\left(\mathrm{H}_{2} \mathrm{NCHO}\right)$ from carbon monoxide (CO) and ammonia $\left(\mathrm{NH}_{3}\right)$ [19] have been observed under low-energy electron irradiation in cryogenic condensed ices con-

\footnotetext{
a e-mail: swiderek@uni-bremen.de (corresponding author)
}

taining the starting compounds. It was proposed in all three cases that electron ionization (EI) of one of the reactants creates an attractive force between adjacent molecules. This initiates a reaction sequence in which bonds form between the reactants, one of the hydrogen atoms migrates and the resulting product radical cation is neutralized by thermalized electrons thus leading to the neutral stable product.

While this ionization-driven reaction mechanism is temptingly simple, a deeper insight into the reactions occurring in the ice mixtures is of utmost importance to arrive at a comprehensive understanding of the electron-induced chemistry in ices. The potential complexity of the reaction networks is obvious considering the wealth of products that can be formed even in a pure ice as exemplified by the case of pure methanol $\left(\mathrm{CH}_{3} \mathrm{OH}\right)$ ice $[15,20]$. As another example, ethanol $\left(\mathrm{C}_{2} \mathrm{H}_{5} \mathrm{OH}\right)$ formation was also observed as consequence of electron attachment (EA) to $\mathrm{C}_{2} \mathrm{H}_{4}$ in the presence of $\mathrm{H}_{2} \mathrm{O}$ [18] indicating that different reaction mechanisms can contribute to the formation of a particular product.

In an effort to unravel electron-induced chemistry in ices, we have recently conducted comprehensive studies by post-irradiation thermal desorption spectrometry (TDS) on thin layers of different pure and mixed ices [20-23]. In each case, the dependence of product formation on electron energy was monitored for several products. This approach not only gives insight into the electron-molecule interactions that initiate the forma- 
tion of the products by releasing reactive intermediate species. It also allows us to draw conclusions on the reaction mechanisms that occur after this initial event. This is achieved by comparing the energy dependences of different products that are potentially formed via the same intermediates. Most interestingly, resonance structures around $10 \mathrm{eV}$ in the energy dependences have suggested that dissociative electron attachment (DEA) to $\mathrm{CO}$ leads to formation of formic acid $(\mathrm{HCOOH})$ in mixtures of $\mathrm{CO}$ and $\mathrm{H}_{2} \mathrm{O}$ [22] and of methyl formate $\left(\mathrm{CH}_{3} \mathrm{OCHO}\right)$ in mixed ices of $\mathrm{CO}$ and $\mathrm{CH}_{3} \mathrm{OH}$ [23]. Here, we substantiate the claim that DEA to CO is an efficient pathway to product formation in ices. To this end, we present new results on mixed $\mathrm{CO}$ and $\mathrm{NH}_{3}$ ices that reveal the role of DEA to $\mathrm{CO}$ in electron-induced chemistry by monitoring the formation of hydrogen cyanide HCN. Furthermore, we compare the results on $\mathrm{CO} / \mathrm{H}_{2} \mathrm{O}$ and $\mathrm{CO} / \mathrm{CH}_{3} \mathrm{OH}$ ices $[22,23]$ with the data on mixed ices where $\mathrm{CO}$ is replaced by $\mathrm{C}_{2} \mathrm{H}_{4}[18,21]$ to demonstrate that a resonance around $10 \mathrm{eV}$ is only visible when CO is present. We thus show that DEA to CO plays an important role in electron-induced syntheses in molecular ices and propose mechanisms for the reactions that are initiated by the fragments resulting from DEA.

\section{Experimental}

The electron energy-dependent formation of products upon electron irradiation of condensed molecular ices was monitored by post-irradiation thermal desorption spectrometry (TDS). The experimental procedures were described in detail previously [16-23]. Briefly, all experiments were performed in an ultrahigh vacuum chamber with a base pressure of $10^{-10}$ mbar. Molecular ices were prepared by leaking vapours of the reactants onto a Ta substrate (this work and Refs. [19-23]) or an Au substrate (Refs. [16-19]) held at $\sim 30-35 \mathrm{~K}$ either as a gas mixture or sequentially, the latter relying on rapid diffusion into pores of the first component. The amounts of gases leaked into the chamber were monitored as pressure drop in the gas handling manifold measured with an MKS Baratron type 622B capacitance manometer. Film thickness was estimated from TDS for the individual components by observing at which pressure drop the transition from monolayer to multilayer desorption signal occurs. TDS data were acquired by resistively heating the substrate with heating rates of $\sim 1 \mathrm{~K} / \mathrm{s}$ while monitoring characteristic $\mathrm{m} / \mathrm{z}$ ratios of the investigated neutral desorbing species using a quadrupole mass spectrometer (QMS) residual gas analyser (Stanford Research System RGA 200). The QMS has an electron-impact ion source operating at an electron energy of $70 \mathrm{eV}$.

The targeted mixing ratio of the two components in the ice can be established by different procedures. In the simplest case, a 1:1 gas mixture was leaked with the aim of producing an ice layer of the same composition. This procedure was applied previously for $\mathrm{C}_{2} \mathrm{H}_{4} / \mathrm{NH}_{3}$

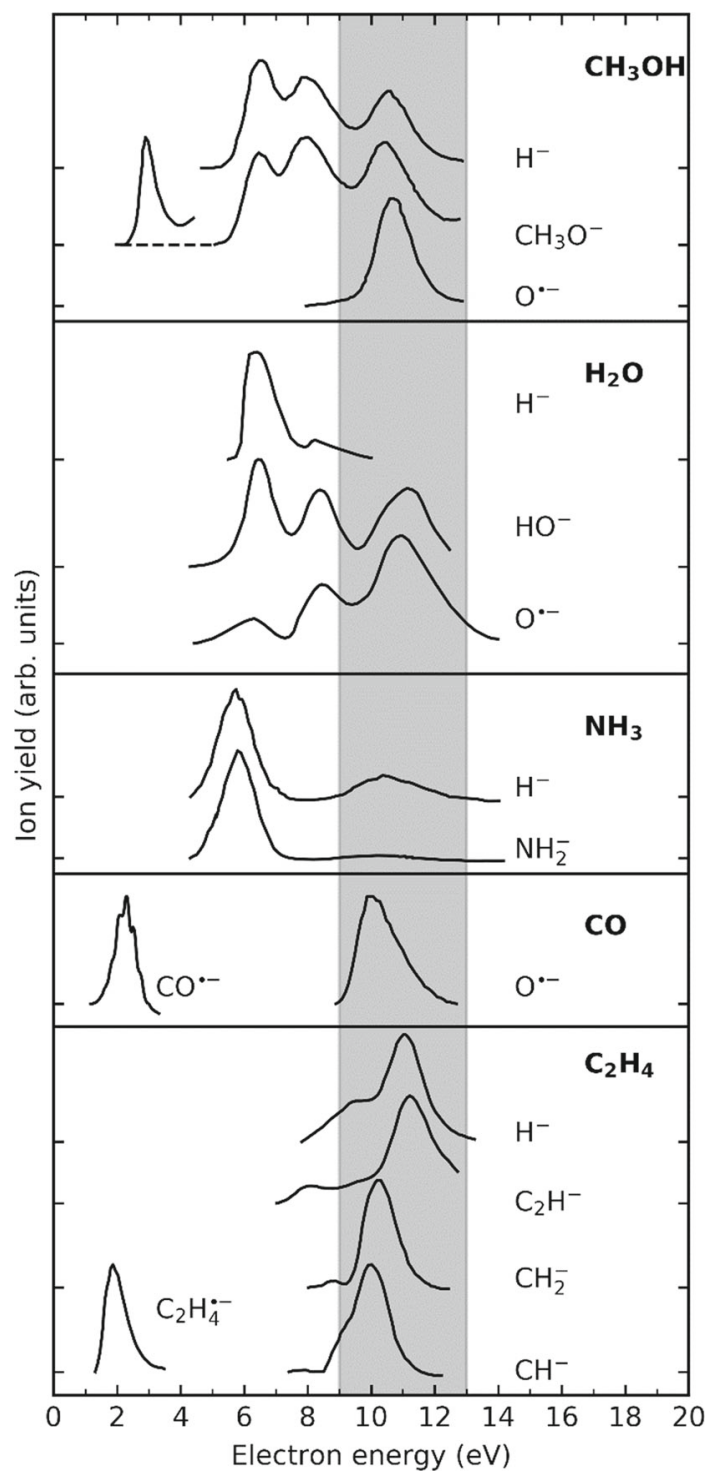

Fig. 1 Overview of gas phase dissociative electron attachment to $\mathrm{CH}_{3} \mathrm{OH}$ (from Ref. [24] reporting DEA ion yields in arbitrary units), $\mathrm{H}_{2} \mathrm{O}$ (from Ref. [25] reporting absolute DEA cross sections), $\mathrm{NH}_{3}$ (from Ref. [26] reporting absolute DEA cross sections), CO (10 eV resonance from Ref. [27] reporting DEA ion yields in arbitrary units), and $\mathrm{C}_{2} \mathrm{H}_{4}(10$ $\mathrm{eV}$ resonance from Refs. $[28,29]$ reporting $\mathrm{DEA}$ ion yields in arbitrary units). In the case of $\mathrm{C}_{2} \mathrm{H}_{4}$, only the most intense signals are displayed. See Ref. [30] for data on minor fragments. Also included is non-dissociative electron attachment at $2 \mathrm{eV}$ to $\mathrm{CO}$ (from Ref. [31] reporting charge trapping in arbitrary units) and $\mathrm{C}_{2} \mathrm{H}_{4}$ (from Ref. [32] derived from energy-dependent cross section for vibrational excitation). Each curve has been normalized to its maximum. The figure does not represent the relative yields of individual fragments from same molecule but merely serves to illustrate to resonance positions. Tick marks on the $y$-axis indicate the vertical offset

[17], $\mathrm{C}_{2} \mathrm{H}_{4} / \mathrm{H}_{2} \mathrm{O}$ [18], as well as $\mathrm{C}_{2} \mathrm{H}_{4} / \mathrm{CH}_{3} \mathrm{OH}$ [21] ices. The actual stochiometric ratio of the two reactants in the ice can be deduced by integrating the area under 

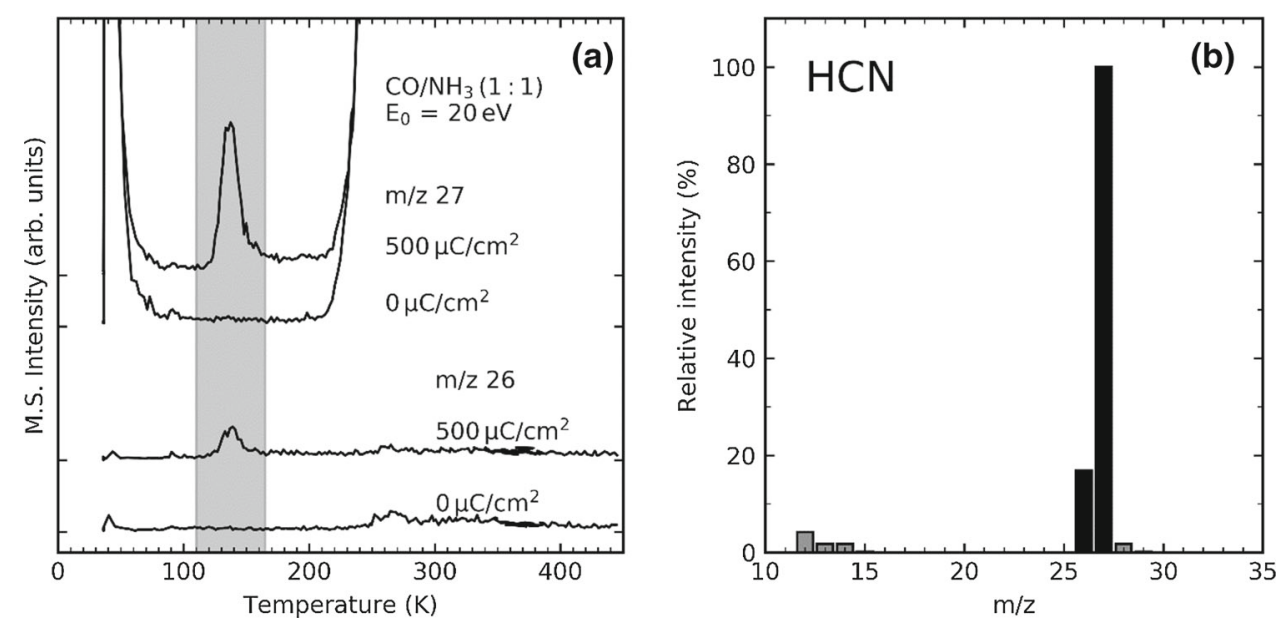

Fig. 2 a Thermal desorption spectra of $\mathrm{CO} / \mathrm{NH}_{3}$ mixed ice (thickness 10-14 monolayers) without electron exposure (denoted $0 \mu \mathrm{C} / \mathrm{cm}^{2}$ ) and after electron irradiation with $500 \mu \mathrm{C} / \mathrm{cm}^{2}$ at an electron energy $\left(E_{0}\right)$ of $20 \mathrm{eV}$. The peaks at $\sim 133 \mathrm{~K}$ in the $\mathrm{m} / z 26$ and 27 curves were assigned to $\mathrm{HCN}$. The signals at $\sim 50 \mathrm{~K}$ and above $220 \mathrm{~K}$ in the $m / z 27$ curve result from desorption of $\mathrm{CO}$ from the ice and from parts of the sample holder that warm up more slowly than the Ta foil itself. CO is detected at $\mathrm{m} / z 27$ due to its high abundance which leads to spillover of intensity to mass channels adjacent to the main signal at $m / z 28$. Tick marks on the vertical axis indicate the baseline level. b Reference mass spectrum of HCN $[35]$

the TDS curves and correcting for the partial electron ionization cross sections of the characteristic fragments that are monitored in the QMS [21]. The thus determined ice composition may deviate from the mixing ratio of the gases if one of the compounds adsorbs more strongly to the walls of the gas injection tube and to parts of the vacuum chamber than the other. In the case of $\mathrm{C}_{2} \mathrm{H}_{4} / \mathrm{CH}_{3} \mathrm{OH}$ ice, the gas mixture was consequently adjusted to produce a 1:1 composition of the ice [21]. Alternatively, the two components can be leaked sequentially. This is advantageous when one component tends to form a porous ice such as $\mathrm{H}_{2} \mathrm{O}$. The pores can then accommodate the molecules of the subsequently dosed gas and this can enhance its sticking probability. This procedure was applied previously to prepare $\mathrm{CO} / \mathrm{H}_{2} \mathrm{O}$ ices [22] and also to study the formation of $\mathrm{HCN}$ in $\mathrm{CO} / \mathrm{NH}_{3}$ ices reported herein. In detail, the ice was prepared by leaking first an amount of $\mathrm{NH}_{3}$ corresponding to a pressure drop of 28 mTorr in the manifold followed by CO (15 mTorr). According to TDS, this produced an ice with a comparable composition as used previously to investigate the formation of formamide [19].

Electron irradiation was performed using a commercial STAIB NEK-150-1 electron source with an energy resolution of $0.5 \mathrm{eV}$. After irradiation, the ice was desorbed in a TDS experiment, again with a heating rate of $\sim 1 \mathrm{~K} / \mathrm{s}$, while monitoring characteristic $\mathrm{m} / z$ ratios of the investigated neutral reaction products. After each experiment, the substrate temperature was held at $450 \mathrm{~K}$ for 2 min to desorb remaining species on the sample holder, which warms up more slowly than the substrate. A relative product yield was obtained by integrating the area under the characteristic desorption signals in the TDS curves. Typically, the same experiment was repeated three to four times to establish an experimental error. This overall procedure was then repeated for a range of electron energies to obtain energy-dependent product yields. Here, attention was paid to select an electron exposure that falls within the linear regime where product yields increase linearly with exposure. This ensures that the product yields obtained at different electron energies can be directly compared.

\section{Results and discussion}

\subsection{DEA processes of the investigated molecular ice constituents}

As a reference for the discussion of resonant product formation in the molecular ices studied herein, Fig. 1 provides an overview of the gas phase DEA processes of the individual ice components. It is wellestablished that the energetic position and the cross sections of the individual DEA channels can change in a condensed environment, the latter even by orders of magnitude $[2,33]$. Nonetheless, the overview given in Fig. 1 clearly illustrates the wealth of DEA processes that exist in the vicinity of $10 \mathrm{eV}$ (grey band in Fig. 1). In fact, in both $\mathrm{CO} / \mathrm{H}_{2} \mathrm{O}$ and $\mathrm{CO} / \mathrm{CH}_{3} \mathrm{OH}$ mixed ices, both components exhibit DEA resonances around this energy. The position of the maximum product yield alone is therefore not a sufficient criterion to identify which DEA channel enhances the formation of a particular product in a mixed ice. Moreover, we note that electron-stimulated desorption of $\mathrm{O}^{--}$from condensed multilayer films of $\mathrm{CO}$ is reso- 

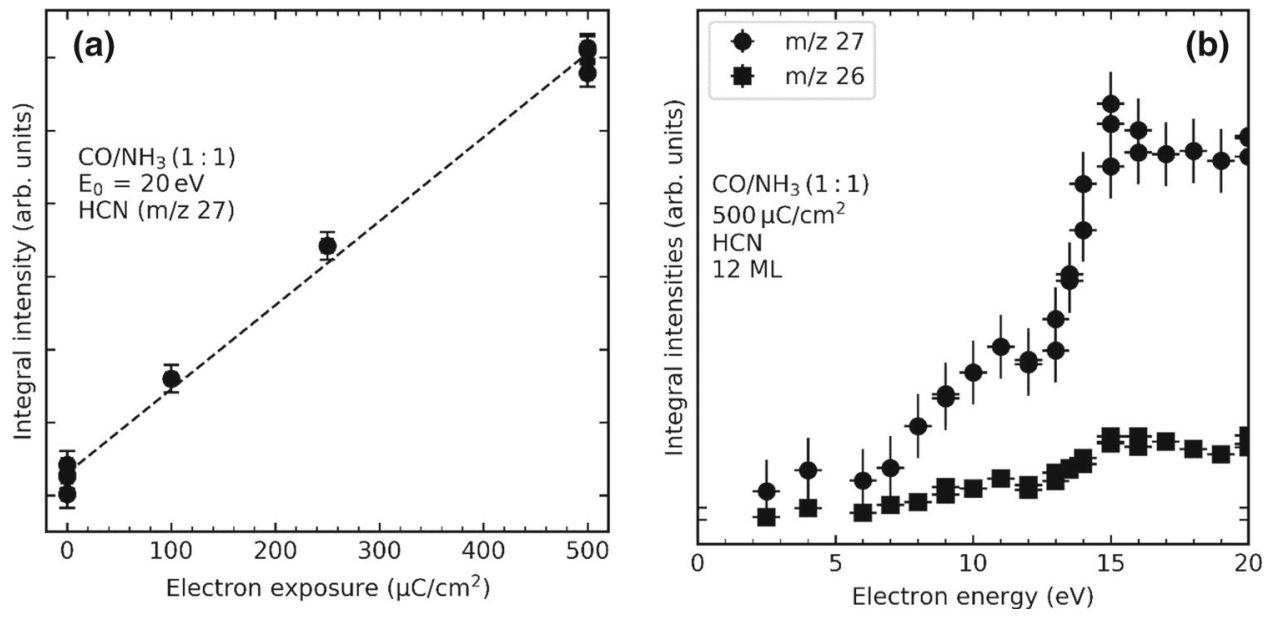

Fig. 3 a Peak areas for the $m / z 27$ desorption signal of HCN at $133 \mathrm{~K}$ obtained by TDS without electron exposure (plotted at $0 \mu \mathrm{C} / \mathrm{cm}^{2}$ ) and after increasing electron irradiation of $\mathrm{CO} / \mathrm{NH}_{3}$ mixed ice at an electron energy $\left(\mathrm{E}_{0}\right)$ of $20 \mathrm{eV}$. Error bars denote the estimated error for the peak area. b Energy dependence of the relative yield of $\mathrm{HCN}$ formed after electron irradiation of $\mathrm{CO} / \mathrm{NH}_{3}$ ice with an electron dose of $500 \mu \mathrm{C} / \mathrm{cm}^{2}$ as derived from the integrated $\mathrm{m} / z 27$ and $\mathrm{m} / z 26$ desorption signals. The thickness of the ice layer was 10-14 monolayers. Tick marks on the vertical axes indicate a peak area of zero

nantly enhanced around $12 \mathrm{eV}[34,35]$ and thus about $2 \mathrm{eV}$ above the maximum product yield in the mixed ices described above. Also, and in contrast to the gas phase, ESD from condensed $\mathrm{CO}$ evinces a second resonance around $16 \mathrm{eV}[34,35]$. We demonstrate in the following that these DEA channels indeed play a role in the investigated mixed ices. The neutral $\mathrm{C}$ fragment leads to the production of $\mathrm{HCN}$ in $\mathrm{CO} / \mathrm{NH}_{3}$ ice (Sect. 3.2) while the $\mathrm{O}^{-}$radical anion initiates both the formation of formic acid $(\mathrm{HCOOH})$ in $\mathrm{CO} / \mathrm{H}_{2} \mathrm{O}$ ice and methyl formate $\left(\mathrm{CH}_{3} \mathrm{OCHO}\right)$ in $\mathrm{CO} / \mathrm{CH}_{3} \mathrm{OH}$ ice (Sect. 3.3).

\subsection{Molecular synthesis triggered by the neutral C fragment}

The electron-induced chemistry of $\mathrm{CO} / \mathrm{NH}_{3}$ mixed ice has been investigated previously with particular focus on the formation of $\mathrm{H}_{2} \mathrm{NCHO}$ [19]. A resonant enhancement of this product was observed in a broad range around $10 \mathrm{eV}$. Aiming at a more comprehensive insight, we have now investigated the production of $\mathrm{HCN}$ in $\mathrm{CO} / \mathrm{NH}_{3}$ ice and its dependence on the electron energy. Figure 2a shows representative TDS data obtained before and after electron irradiation at $20 \mathrm{eV}$. A distinct desorption signal with maximum at $133 \mathrm{~K}$ is seen in the TDS curves obtained for both $m / z 26$ and 27 . The relative intensity of these signals is $1: 5$ and thus very similar to the intensity ratio of these two signals in a reference mass spectrum of HCN [36] (Fig. 2b) indicating that this product is indeed formed under electron irradiation of the $\mathrm{CO} / \mathrm{NH}_{3}$ ice.

To establish the relative product yields as function of electron energy, the area under the TDS signal at $133 \mathrm{~K}$ in the $m / z 27$ data was evaluated. First, it was verified that the exposure of $500 \mu \mathrm{C} / \mathrm{cm}^{2}$ applied in Fig. 2a falls within the linear regime so that electron- induced depletion of the reactants $\mathrm{CO}$ and $\mathrm{NH}_{3}$ as well as decomposition of the product HCN can still be neglected. Therefore, the integral intensity of the desorption signal was first plotted for increasing electron exposure at $20 \mathrm{eV}$ (Fig. 3a). The product yield in fact increases linearly with electron exposure. As reaction rates are typically lower at lower electron energies, an electron exposure of $500 \mu \mathrm{C} / \mathrm{cm}^{2}$ was thus also used in all subsequent experiments at lower electron energies. The resulting energy-dependent integral desorption signals of HCN are shown in Fig. 3b. The constant intensity ratio between the signals at $\mathrm{m} / z 27$ and $\mathrm{m} / z 26$ shows that the data are representative of $\mathrm{HCN}$ at all electron energies. The curves evince resonant enhancement of the product yield around $11 \mathrm{eV}$ and $15 \mathrm{eV}$. DEA processes in $\mathrm{NH}_{3}$ that could contribute to this enhancement have been reported around $10 \mathrm{eV}$ (see Fig. 1) but not at higher energy. In contrast, apart from a shift to lower energy, the resonances observed here compare well with the maxima in the ESD yields of $\mathrm{O}^{--}$from condensed multilayer films of $\mathrm{CO}$ around $12 \mathrm{eV}$ and $16 \mathrm{eV}[34,35]$. This shift is rationalized by considering that desorption of the anion requires a certain excess energy to overcome the polarization forces in the condensed phase. In contrast, $\mathrm{HCN}$ is produced within the layer and the energy required for desorption is supplied thermally in the subsequent TDS experiment. We thus conclude that DEA to CO is the initiating electronmolecule interaction that leads to the formation of $\mathrm{HCN}$ in the $\mathrm{CO} / \mathrm{NH}_{3}$ mixed ice. We propose that the neutral $\mathrm{C}$ fragment released together with $\mathrm{O}^{-}$upon DEA to $\mathrm{CO}$ reacts with $\mathrm{NH}_{3}$ by insertion into one of the N$\mathrm{H}$ bonds and subsequent elimination of $\mathrm{H}_{2}$ to produce HCN (Fig. 4) as also reported earlier [37]. 


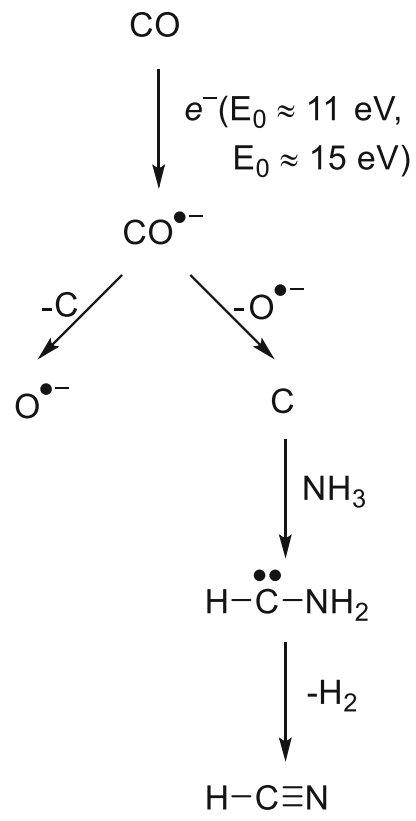

Fig. 4 Proposed reaction mechanism for the electroninduced formation of $\mathrm{HCN}$ in $\mathrm{CO} / \mathrm{NH}_{3}$ mixed ice

\subsection{Molecular synthesis triggered by the $\mathrm{O}^{-}$radical anion fragment}

Figure 5a shows the energy-dependent yield of $\mathrm{HCOOH}$ in mixed $\mathrm{CO} / \mathrm{H}_{2} \mathrm{O}$ ice $[22]$ and Fig. 5b the yield of $\mathrm{CH}_{3} \mathrm{OCHO}$ in $\mathrm{CO} / \mathrm{CH}_{3} \mathrm{OH}$ ice [23], both obtained from the areas under the characteristic TDS signals. For comparison, the data for ices in which $\mathrm{CO}$ is replaced by $\mathrm{C}_{2} \mathrm{H}_{4}[18,21]$ is also included. For details of the experiments and data analysis we refer to the previous studies [18,21-23]. The resonant enhancement of the yields of $\mathrm{HCOOH}$ and $\mathrm{CH}_{3} \mathrm{OCHO}$ around $10 \mathrm{eV}$ clearly indicates that an electron attachment process contributes to the product formation. We show now that the sequence of reactions leading to these products must be initiated by the $\mathrm{O}^{-}$radical anion resulting from DEA to $\mathrm{CO}$. This is, however, not a priori obvious. In fact, both $\mathrm{H}_{2} \mathrm{O}$ and $\mathrm{CH}_{3} \mathrm{OH}$ also exhibit DEA channels in this energy range (Fig. 1). Furthermore, as discussed in Sect. 3.1, both the energies and the cross sections of DEA processes can change under the effect of the condensed medium.

The formation of $\mathrm{HCOOH}$ and $\mathrm{CH}_{3} \mathrm{OCHO}$ through DEA must involve reactions of radical species with CO. This should be more favourable than reactions of negative ion fragments with the electron-rich $\mathrm{CO}$ molecule. Regarding $\mathrm{HCOOH}$ formation in $\mathrm{CO} / \mathrm{H}_{2} \mathrm{O}$ mixed ice, gas phase data suggest that DEA to $\mathrm{H}_{2} \mathrm{O}$ around $10 \mathrm{eV}$ produces either $\mathrm{O}^{-}$or $\mathrm{OH}^{-}$, the latter accompanied by release of $\mathrm{H}^{-}$(Fig. 1). In the mixed ice, $\mathrm{H}^{\circ}$ can react with $\mathrm{CO}$ to yield the $\mathrm{HCO}^{\circ}$ radical. This radical is a key intermediate to the formation of formaldehyde $\left(\mathrm{H}_{2} \mathrm{CO}\right)$ as has also been deduced from the finding that $\mathrm{H}_{2} \mathrm{CO}$ is resonantly formed around $4 \mathrm{eV}$ [22] (see also Fig. 6). It was proposed that at this energy, the $\mathrm{HCO}^{\circ}$ radical results from electron attachment (EA) to $\mathrm{CO}$ yielding the $\mathrm{CO}^{--}$radical anion which in turn acts as a strong base and is thus converted to the $\mathrm{HCO}^{\circ}$ radical by transfer of a proton from $\mathrm{H}_{2} \mathrm{O}$. However, a corresponding resonant structure at $4 \mathrm{eV}$ was not observed in the yield of $\mathrm{HCOOH}$ (Fig. 6) thus ruling out its formation by reaction of $\mathrm{HCO}^{\prime}$ with $\mathrm{H}_{2} \mathrm{O}$. Therefore, the DEA channel near $10 \mathrm{eV}$ yielding $\mathrm{OH}^{-}$and $\mathrm{H}^{-}$cannot account for the $10 \mathrm{eV}$ resonant signal in the yield of $\mathrm{HCOOH}$ (Fig. 5a, bottom and Fig. 6) and is also not dominant with respect to the formation of $\mathrm{H}_{2} \mathrm{CO}$ (Fig. 6). In consequence, DEA yielding $\mathrm{O}^{--}$is the most conceivable reaction channel leading to $\mathrm{HCOOH} . \mathrm{O}^{--}$can accept a proton from $\mathrm{H}_{2} \mathrm{O}$ to yield $\mathrm{HO}^{\circ}$ which in turn can add to $\mathrm{CO}$ yielding a $\mathrm{HOCO}^{\circ}$ radical. The latter can react with further $\mathrm{H}_{2} \mathrm{O}$ to yield the product $\mathrm{HCOOH}$.

Having identified $\mathrm{O}^{--}$as the most likely species to initiate formation of $\mathrm{HCOOH}$ in $\mathrm{CO} / \mathrm{H}_{2} \mathrm{O}$ ice alone, however, does not provide a unique assignment of the DEA process that initiates the formation of $\mathrm{HCOOH}$. In the gas phase, $\mathrm{O}^{-}$is produced both by DEA to $\mathrm{CO}$ around $10 \mathrm{eV}$ and to $\mathrm{H}_{2} \mathrm{O}$ at slightly higher energy (Fig. 1). Considering again that gas phase resonance energies can be shifted and cross sections modified in an ice layer $[2,33]$, it was thus previously unclear which of these DEA processes drives the formation of $\mathrm{HCOOH}$ [22]. A comparison with the energy dependent yield of $\mathrm{C}_{2} \mathrm{H}_{5} \mathrm{OH}$ in mixed ices of $\mathrm{C}_{2} \mathrm{H}_{4}$ and $\mathrm{H}_{2} \mathrm{O}$ [18] can resolve this question (Fig. 5a). The decisive step in the formation of $\mathrm{C}_{2} \mathrm{H}_{5} \mathrm{OH}$ is the addition of $\mathrm{HO}$ radicals to the double bond $\mathrm{C}_{2} \mathrm{H}_{4}$ [18]. As noted above, HO can be formed by reaction of $\mathrm{O}^{--}$with $\mathrm{H}_{2} \mathrm{O}$. However, a resonant enhancement around $10 \mathrm{eV}$ is absent from the energy-dependent yield of $\mathrm{C}_{2} \mathrm{H}_{5} \mathrm{OH}$ (Fig. 5a, top). Instead, the yield of $\mathrm{C}_{2} \mathrm{H}_{5} \mathrm{OH}$ increases steadily above $8 \mathrm{eV}$ (Fig. 5a) pointing to a process initiated by EI or possibly ND. Comparing the cases of $\mathrm{CO} / \mathrm{H}_{2} \mathrm{O}$ mixed ice with the $\mathrm{C}_{2} \mathrm{H}_{4} / \mathrm{H}_{2} \mathrm{O}$ ice thus gives evidence that $\mathrm{O}^{--}$ must be formed with much higher yield by DEA to CO than to $\mathrm{H}_{2} \mathrm{O}$ in the mixed ice. In conclusion, DEA to $\mathrm{CO}$ is the initiating electron-molecule interaction that leads to formation of $\mathrm{HCOOH}$ in the $\mathrm{CO} / \mathrm{H}_{2} \mathrm{O}$ mixed ice. We note that $\mathrm{C}^{-}$has also been observed in ESD from condensed multilayer films of $\mathrm{CO}$ but with yield peaking at $14 \mathrm{eV}$ and thus about $2 \mathrm{eV}$ higher than that of $\mathrm{O}^{--}$[34]. In contrast, the energetic shift between the maximum yield of $\mathrm{HCOOH}$ at $10 \mathrm{eV}$ and the resonance position in ESD of $\mathrm{O}^{--}$is in line with the earlier conclusion that the ion needs about $2 \mathrm{eV}$ excess energy to be able to desorb [34]. Therefore, we rule out a significant contribution of the resonance producing $\mathrm{C}^{-}$to the formation of $\mathrm{HCOOH}$ around $10 \mathrm{eV}$ seen in Figs. 5a and 6.

In the case of the $\mathrm{CO} / \mathrm{CH}_{3} \mathrm{OH}$ mixed ice [23], DEA channels of $\mathrm{CH}_{3} \mathrm{OH}$ near $10 \mathrm{eV}$ lead to $\mathrm{H}^{-}$accompanied by $\mathrm{CH}_{3} \mathrm{O}$ or fragments thereof, to $\mathrm{CH}_{3} \mathrm{O}^{-}$and $\mathrm{H}^{-}$, or to $\mathrm{O}^{--}$and corresponding neutral species (Fig. 1). Again, it is therefore not immediately obvious if DEA to $\mathrm{CO}$ or to $\mathrm{CH}_{3} \mathrm{OH}$ triggers the resonant production of $\mathrm{CH}_{3} \mathrm{OCHO}$ around $10 \mathrm{eV}$ (Fig. 5b, top). A dominant contribution of the $\mathrm{CH}_{3} \mathrm{O}^{-}$and $\mathrm{H}^{-}$DEA chan- 

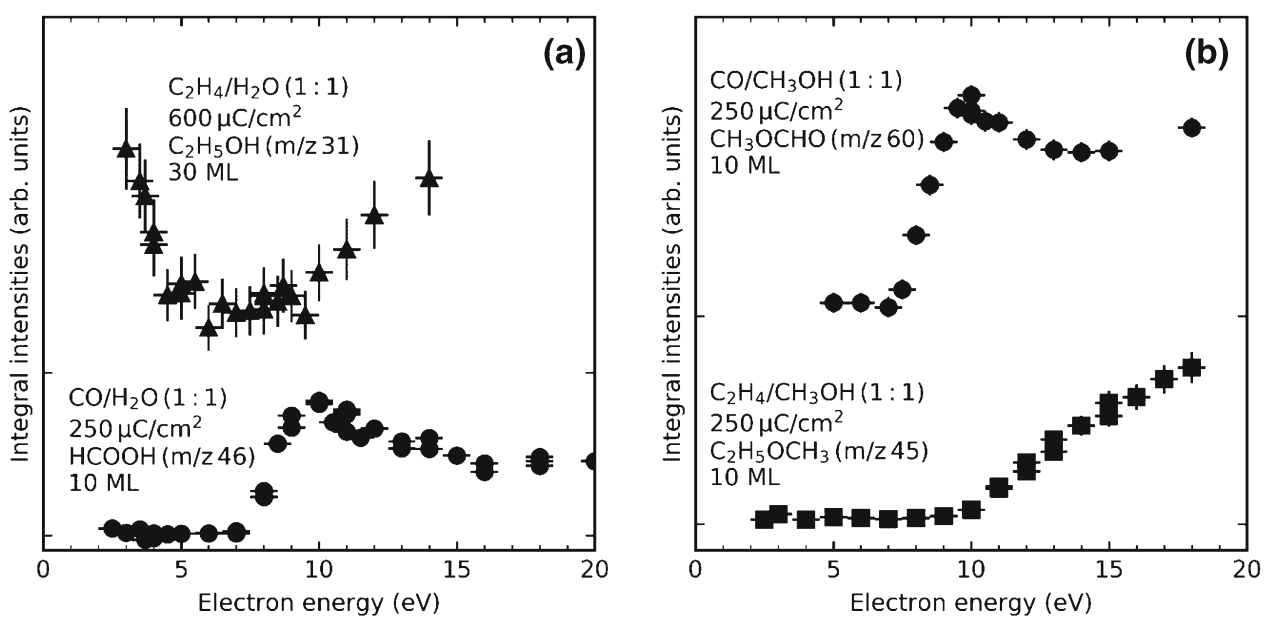

Fig. 5 Electron-energy dependent yields of product formation upon electron irradiation of different mixed ices: a $\mathrm{HCOOH}$ in $\mathrm{CO} / \mathrm{H}_{2} \mathrm{O}$ ice (bottom, from Ref. [22]) and $\mathrm{C}_{2} \mathrm{H}_{5} \mathrm{OH}$ in mixed $\mathrm{C}_{2} \mathrm{H}_{4} / \mathrm{H}_{2} \mathrm{O}$ ice (top, from Ref. [18]), b CH $\mathrm{CHCHO}_{3} \mathrm{On}$ $\mathrm{CO} / \mathrm{CH}_{3} \mathrm{OH}$ ice (top, from Ref. [23]) and $\mathrm{C}_{2} \mathrm{H}_{5} \mathrm{OCH}_{3}$ in $\mathrm{C}_{2} \mathrm{H}_{4} / \mathrm{CH}_{3} \mathrm{OH}$ ice (bottom, from Ref. [21]). The thickness of the ice layers in monolayers (ML) is stated in the figures. In each set of experiments, the electron exposures were sufficiently small to ensure that the product formation increased linearly with exposure. Product yields at different energies thus reflect the relative values of the cross section for formation of each particular product. For details of the experiments see [18,21-23]

nel has been excluded. This was again deduced from the lack of resonant formation of the concurrent product $\mathrm{H}_{2} \mathrm{CO}$ [23], anticipated to be produced by reaction of $\mathrm{H}^{*}$ with $\mathrm{CO}$ and subsequent abstraction of a hydrogen atom from $\mathrm{CH}_{3} \mathrm{OH}$ by the resulting $\mathrm{HCO}$. radical. It is, however, more difficult to identify which of the remaining DEA channels is responsible for formation of $\mathrm{CH}_{3} \mathrm{OCHO}$. This product results when a $\mathrm{CH}_{3} \mathrm{O}^{\circ}$ radical adds to $\mathrm{CO}$ to produce $\mathrm{CH}_{3} \mathrm{OCO}{ }^{*}$ which, in turn, abstracts a hydrogen atom from an adjacent $\mathrm{CH}_{3} \mathrm{OH}$ molecule to yield the final product. $\mathrm{CH}_{3} \mathrm{O}$. can result directly from DEA to $\mathrm{CH}_{3} \mathrm{OH}$ or via reaction of $\mathrm{O}^{--}$with $\mathrm{CH}_{3} \mathrm{OH}$. Note again that $\mathrm{O}^{--}$is potentially formed by DEA to both $\mathrm{CH}_{3} \mathrm{OH}$ and $\mathrm{CO}$. These different reaction pathways can again be distinguished by comparing with the $\mathrm{C}_{2} \mathrm{H}_{4} / \mathrm{CH}_{3} \mathrm{OH}$ mixed ice (Fig. 5b, bottom). Here, addition of $\mathrm{CH}_{3} \mathrm{O}^{-}$to $\mathrm{C}_{2} \mathrm{H}_{4}$ and abstraction of hydrogen from an adjacent molecule yields $\mathrm{CH}_{3} \mathrm{OC}_{2} \mathrm{H}_{5}$ [21]. However, as deduced from the threshold-type behavior of the energy dependent product yield, this reaction is not dominated by DEA (see also [21]). In conclusion, this supports again that DEA to $\mathrm{CO}$ rather than DEA to $\mathrm{CH}_{3} \mathrm{OH}$ is responsible for the $10 \mathrm{eV}$ resonant enhancement of the yield of $\mathrm{CH}_{3} \mathrm{OCHO}$ in $\mathrm{CO} / \mathrm{CH}_{3} \mathrm{OH}$ mixed ice (Fig. 5b, top). Overall, the comparison of different ice systems provides clear evidence that the $\mathrm{O}^{-}$DEA fragment from $\mathrm{CO}$ activates molecules such as $\mathrm{H}_{2} \mathrm{O}$ and $\mathrm{CH}_{3} \mathrm{OH}$ to initiate further chemical reactions. DEA to CO thus plays a dominant role in the electron-induced synthesis of larger products.

We finally comment on the different energetic position of the resonance maximum in the case of reactions driven by $\mathrm{O}^{--}(10 \mathrm{eV})$ and the first maximum of the HCN production driven by the neutral $\mathrm{C}$ fragment $(11 \mathrm{eV})$. It is possible that, in the latter case, the resonant process overlaps with contributions of ND and/or

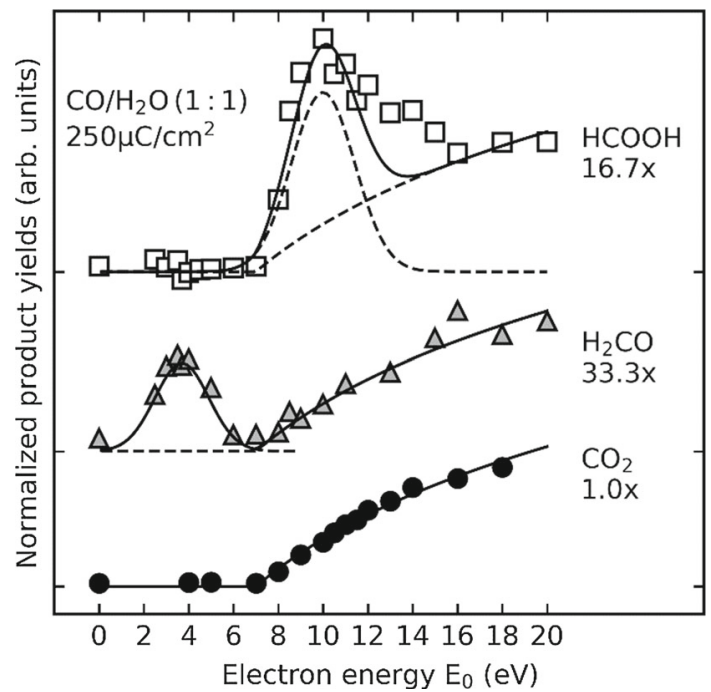

Fig. 6 Energy dependence of the relative yields of $\mathrm{CO}_{2}$, $\mathrm{HCOOH}$, and $\mathrm{H}_{2} \mathrm{CO}$ formed after electron irradiation of mixed $\mathrm{CO} / \mathrm{H}_{2} \mathrm{O}$ ice with an electron dose of $250 \mu \mathrm{C} / \mathrm{cm}^{2}$. Adapted with permission from Ref. [22]. Copyright 2019 American Chemical Society

DI that distort the DEA signal. As another explanation, the reactions initiated by $\mathrm{O}^{--}$and $\mathrm{C}$ may encounter differently high activation barriers. However, a comprehensive evaluation of this effect is beyond the scope of this work.

\section{Conclusions}

We have provided evidence that DEA to CO in mixed molecular ices is an important initiating electron- 
molecule interaction leading to different reaction products. In the case of mixed $\mathrm{CO} / \mathrm{NH}_{3}$ ice, the neutral carbon fragment resulting from DEA to $\mathrm{CO}$ reacts with $\mathrm{NH}_{3}$ to yield HCN. This is supported by the observed resonant enhancement of the $\mathrm{HCN}$ yield around $11 \mathrm{eV}$ and $15 \mathrm{eV}$ which is in good agreement with earlier ESD studies on condensed $\mathrm{CO}[34,35]$. In $\mathrm{CO} / \mathrm{H}_{2} \mathrm{O}$ and $\mathrm{CO} / \mathrm{CH}_{3} \mathrm{OH}$ ices $[22,23]$, the corresponding anionic DEA fragment $\mathrm{O}^{--}$initiates reactions leading to the formation of $\mathrm{HCOOH}$ and $\mathrm{CH}_{3} \mathrm{OCHO}$, respectively. This is evident from the comparison with mixed ices where $\mathrm{CO}$ is replaced by $\mathrm{C}_{2} \mathrm{H}_{4}[18,21]$. In these latter systems, the $10 \mathrm{eV}$ resonance seen in product formation in the ices containing $\mathrm{CO}$ is absent. We thus show that DEA to CO plays an important role in electron-induced syntheses in molecular ices. The understanding gained herein contributes to the general goal to unravel the reactions sequences in astrochemical molecular ices.

Acknowledgements The work presented here was funded by the Deutsche Forschungsgemeinschaft (DFG) under Project Number SW26/15-2.

\section{Author contributions}

FS performed the reevaluation of data for Sect. 3.3 and prepared Figs. 1, 2, 3 and 5, 6. MPM performed and analysed the experiments described in Sect. 3.2 and prepared Fig. 4. JHB supervised all experiments. PS wrote the manuscript. All authors have proof-read and discussed the final version of the manuscript.

Funding Open Access funding enabled and organized by Projekt DEAL.

Data availability statement This manuscript has no associated data or the data will not be deposited. [Authors' comment: The data sets generated during and/or analysed during the current study are available from the corresponding author upon request].

\section{Declarations}

Conflict of interest The authors declare no competing financial interest.

Open Access This article is licensed under a Creative Commons Attribution 4.0 International License, which permits use, sharing, adaptation, distribution and reproduction in any medium or format, as long as you give appropriate credit to the original author(s) and the source, provide a link to the Creative Commons licence, and indicate if changes were made. The images or other third party material in this article are included in the article's Creative Commons licence, unless indicated otherwise in a credit line to the material. If material is not included in the article's Creative Commons licence and your intended use is not permitted by statutory regulation or exceeds the permitted use, you will need to obtain permission directly from the copyright holder.
To view a copy of this licence, visit http://creativecomm ons.org/licenses/by/4.0/.

\section{References}

1. L.G. Christophorou, J.K. Olthoff, Fundamental Electron Interactions with Plasma Processing Gases, 1st edn. (Springer, Boston, 2004)

2. I. Bald, J. Langer, P. Tegeder, O. Ingólfsson, Int. J. Mass Spectrom. 277, 4 (2008)

3. J.W. McConkey, C.P. Malone, P.V. Johnson, C. Winstead, V. McKoy, I. Kanik, Phys. Rep. 466, 1 (2008)

4. C. Winstead, V. McKoy, Radiat. Phys. Chem. 77, 1258 (2008)

5. J.H. Moore, P. Swiderek, S. Matejcik, M. Allan, in Nanofabrication Using Focused Ion and Electron Beams - Principles and Applications, edited by P. Russell, I. Utke, S. Moshkalev, 1st edn. (Oxford University Press, New York, 2012)

6. N.J. Mason, J. Phys.: Conf. Ser. 565, 012001 (2014)

7. R.M. Thorman, T.P. Ragesh Kumar, D.H. Fairbrother, O. Ingólfsson, Beilstein J. Nanotechnol. 6, 1904 (2015)

8. O. Ingólfsson, in Low-Energy Electrons: Fundamentals and Applications, edited by O. Ingólfsson, 1st edn. (Pan Stanford Publishing, Singapore, 2019)

9. A.D. Bass, L. Sanche, Low Temp. Phys. 29, 202 (2003)

10. A. Lafosse, M. Bertin, R. Azria, Prog. Surf. Sci. 84, 177 (2009)

11. C.R. Arumainayagam, H.-L. Lee, R.B. Nelson, D.R. Haines, R.P. Gunawardane, Surf. Sci. Rep. 65, 1 (2010)

12. A. Turchanin, A. Gölzhäuser, Prog. Surf. Sci. 87, 108 (2012)

13. A. Turchanin, Chimia 73, 473 (2019)

14. M.C. Boyer, N. Rivas, A.A. Tran, C.A. Verish, C.R. Arumainayagam, Surf. Sci. 652, 26 (2016)

15. C.R. Arumainayagam, R.T. Garrod, M.C. Boyer, A.K. Hay, S.T. Bao, J.S. Campbell, J. Wang, C.M. Nowak, M.R. Arumainayagam, P.J. Hodge, Chem. Soc. Rev. 48, 2293 (2019)

16. E. Böhler, J. Warneke, P. Swiderek, Chem. Soc. Rev. 42, 9219 (2013)

17. T. Hamann, E. Böhler, P. Swiderek, Angew. Chem. Int. Ed. 48, 4643 (2009)

18. J. Warneke, Z. Wang, P. Swiderek, J.H. Bredehöft, Angew. Chem. Int. Ed. 54, 4397 (2015)

19. J.H.Bredehöft, E.Böhler, F. Schmidt T. Borrmann, P. Swiderek, ACS Earth Space Chem. 1, 50 (2017)

20. F. Schmidt, P. Swiderek, J.H. Bredehöft, ASC Earth Space Chem. 5, 391 (2021)

21. F. Schmidt, P. Swiderek, J.H. Bredehöft, J. Phys. Chem. A 123, 37 (2019)

22. F. Schmidt, P. Swiderek, J.H. Bredehöft, ASC Earth Space Chem. 3, 1974 (2019)

23. F. Schmidt, P. Swiderek, T. Scheele, J.H. Bredehöft, Phys. Chem. Chem. Phys. 23, 11649 (2021)

24. B.C. Ibanescu, O. May, A. Monney, M. Allan, Phys. Chem. Chem. Phys. 9, 3163 (2007)

25. Y. Itikawa, N. Mason, J. Phys. Chem. Ref. Data 34, 1 (2005)

26. P. Rawat, V.S. Prabhudesai, M.A. Rahman, N.B. Ram, E. Krishnakumar, Int. J. Mass Spectrom. 277, 96 (2008) 
27. K. Gope, V. Tadsare, V.S. Prabhudesai, N.J. Mason, E. Krishnakumar, Eur. Phys. J. D 70, 134 (2016)

28. J.C.J. Thynne, K.A.G. MacNeil, J. Phys. Chem. 75, 2584 (1971)

29. L. von Trepka, H. Neuert, Z. Naturforsch. A: Phys. Sci. 18, 1295 (1963)

30. E. Szymańska, N.J. Mason, E. Krishnakumar, C. Matias, A. Mauracher, P. Scheier, S. Denifl, Int. J. Mass Spectrom. 365-366, 356 (2014)

31. R.D. Rempt, Phys. Rev. Lett. 22, 1034 (1969)

32. I.C. Walker, A. Stamatovic, S.F. Wong, J. Chem. Phys. 69, 5532 (1978)
33. A.D. Bass, L. Sanche, Radiat. Environ. Biophys. 37, 243 (1998)

34. L. Sanche, Phys. Rev. Lett. 53, 1638 (1984)

35. R. Azria, L. Parenteau, L. Sanche, J. Chem. Phys. 88, 5166 (1988)

36. NIST Mass Spectrometry Data Center, W. E. Wallace, director, in NIST Chem. WebBook, NIST Stand. Ref. Database Number 69, Eds. P.J. Linstrom W.G. Mallard, Gaithersburg MD, 20899, https://doi.org/10. 18434/T4D303 (retrieved March 13, 2020)

37. P.B. Shevlin, D.W. McPherson, P. Melius, J. Am. Chem. Soc. 105, 488 (1983) 